\title{
Outcomes of Localized Esophageal Squamous Cell Carcinoma Patients Treated With Definitive Concurrent Chemoradiotherapy Using Either Standard or High Radiotherapy Dose: A Retrospective Study Controlling for Organ at Risk Dose
}

\author{
CHIA-CHIN LI ${ }^{1 *}$, HSIN-YUAN FANG ${ }^{2,3 *}$, CHEN-YUAN LIN ${ }^{4 *}$, WEI-CHIH SHEN ${ }^{*}$ and CHUN-RU CHIEN ${ }^{1,3,6}$ \\ ${ }^{1}$ Department of Radiation Oncology, China Medical University Hospital, Taichung, Taiwan, R.O.C.; \\ ${ }^{2}$ Department of Chest Surgery, China Medical University Hospital, Taichung, Taiwan, R.O.C.; \\ ${ }^{3}$ School of Medicine, College of Medicine, China Medical University, Taichung, Taiwan, R.O.C.; \\ ${ }^{4}$ Division of Hematology and Oncology, China Medical University Hospital, Taichung, Taiwan, R.O.C.; \\ ${ }^{5}$ Department of Computer Science and Information Engineering, Asia University, Taichung, Taiwan, R.O.C.; \\ ${ }^{6}$ Department of Radiation Oncology, China Medical University Hsinchu Hospital, Hsinchu, Taiwan, R.O.C.
}

\begin{abstract}
Background/Aim: The optimal radiotherapy dose for localized esophageal squamous cell carcinoma (ESqCC) patients treated with definitive concurrent chemoradiotherapy (CCRT) is debated. The aim of our study was to compare patient outcomes using either standard or high radiotherapy dose. Materials and Methods: Eligible patients diagnosed between 2011 and 2015 from the cancer registry of our Institute were identified and a propensity score (PS)matched cohort (1:1 for high vs. standard dose) was constructed to balance observable potential confounders (including organ at risk dose). The hazard ratio (HR) of death between high and standard dose was compared. Results: Our study population included $73 / 36$ patients beforelafter PS matching. The HR of death at the high dose compared to the standard dose was 0.554 (95\% confidence interval $(C I)=0.308-0.998, p=0.049)$. Conclusion: Definitive CCRT using a high radiotherapy dose showed improved survival outcomes for localized ESqCC patients compared to standard dose.
\end{abstract}

\footnotetext{
\#These Authors contributed equally to this study.

Correspondence to: Chun-Ru Chien, MD, Ph.D., School of Medicine, College of Medicine, China Medical University, No.91 Hsueh-Shih Road, North District, Taichung 40402, Taiwan, R.O.C. Tel: +886 4220521217450, Fax: +886 4220521217460, e-mail: d16181@gmail.com
}

Key Words: Esophageal squamous cell carcinoma, concurrent chemoradiotherapy, radiotherapy dose.
Esophageal cancer is a major cause of cancer-related mortality worldwide $(1,2)$. Squamous cell carcinoma is the predominant malignancy in Asia whereas adenocarcinoma is more common in the western countries $(2,3)$. For late-stage localized esophageal squamous cell carcinoma (ESqCC), definitive concurrent chemoradiotherapy (CCRT) has been suggested as one of the standards-of-care treatments for many years in the North American, European, and Asian guidelines (4-8).

The optimal radiotherapy dose is a hot debate since the publication of INT-0123, a randomized controlled trial (RCT) (9). For example, strictly 50-50.4 Gy were suggested in the North American guideline (5), whereas up to $60 \mathrm{~Gy}$ had been mentioned in the European or Asian guidelines (7, 8). Due to the lack of a new RCT as stated in a systematic review published in 2015 (10) as well as in a review paper published in 2018 (11), many retrospective studies have been performed to address this issue as cited in the above 2018 review (12-14).

In order to appropriately compare patients treated with standard dose with those treated with high dose, patients treated with the standard dose because of organ at risk (OAR) dose constraint have to be excluded (i.e., they were not given high dose due to already high OAR dose even at standard dose). However, these dosimetric criteria were not considered in the above retrospective studies (12-14). Therefore, our study aimed to compare the outcomes of localized ESqCC patients treated with definitive CCRT using either standard or high radiotherapy dose, while controlling for covariables including OAR dose. 


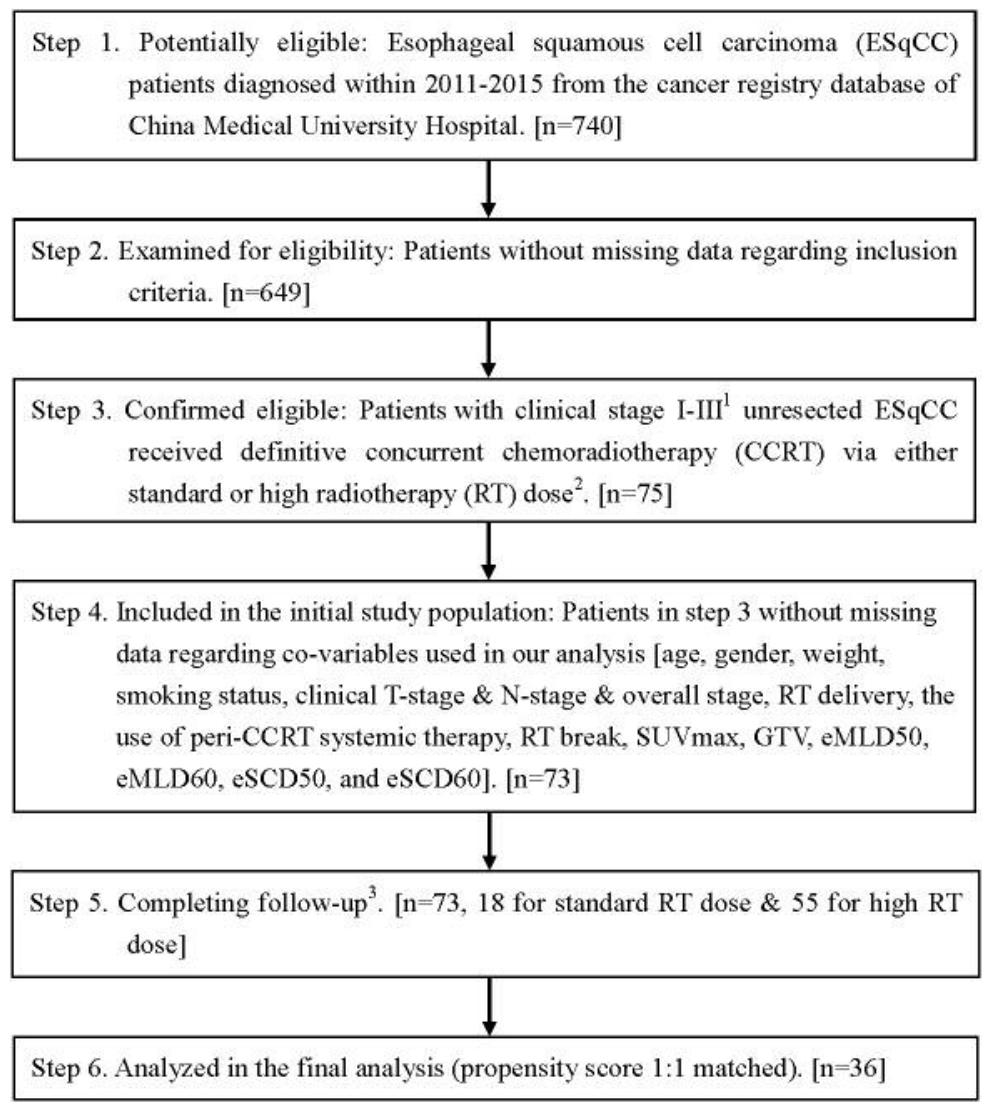

Figure 1. STROBE study flowchart and number of individuals at each stage of the study. ${ }^{1}$ Seventh American Joint Committee on Cancer, T1NO excluded; ${ }^{2} 50 \mathrm{~Gy}$ [standard RT dose] vs. $60 \mathrm{~Gy}$ [high RT dose] in 1.8-2 Gy/fraction, $\pm 5 \%$ in dose; also, critical organ dose within inclusion criteria; ${ }^{3}$ Regarding overall survival (according to death registry).

\section{Materials and Methods}

Study population and study design. In this retrospective study, clinical stage I-III (excluding T1N0) (15) unresected esophageal squamous cell carcinoma adult (age $\geq 18$ years old) patients found in the cancer registry of our institute between 2011-2015 were included. All patients received definitive concurrent chemoradiotherapy with either standard $(50 \mathrm{~Gy}+/-5 \%)$ or high $(60 \mathrm{~Gy}+/-5 \%)$ dose radiotherapy (only via external beam), both in conventional fractionation. In order to make these two groups comparable in the OAR dose, the expected mean lung dose and spinal cord maximal dose were estimated if the radiotherapy plan was delivered for either $50 \mathrm{~Gy}$ (eMLD50 \& eSCD50) or $60 \mathrm{~Gy}$ (eMLD60 \& eSCD60) for each patient via reviewing RT planning record. Patients with eMLD60 >20 Gy or eSCD60 >50 Gy were excluded. Patients with previous cancer(s) or positron emission tomography (PET) not used in staging were also excluded. The date of diagnosis was adopted as the index date. The explanatory variable of interest [standard or high radiotherapy (RT) dose] was determined based on the cancer registry and decided the outcomes [overall survival (OS), progression-free survival (PFS), and esophageal cancer specific survival (ECSS)] using the recording in the cancer registry and the linkage with death registration. Then, potential confounders (see next section) were considered and propensity-score (PS) matched samples were constructed using various PS estimation methods [logistic regression (LR) and machine learning methods, including neural network (NN) \& random forest (RF)], to evaluate the effectiveness of high RT dose (vs. standard RT dose). This study was approved by the research ethics committee of our institute (CMUH104-REC3-087).

Other explanatory covariables. For adjustment of potential nonrandomized treatment selection, other covariables were collected as confounders, including patient demographic factors [age, gender, weight, smoking status], disease characteristics [clinical T-stage, $\mathrm{N}$-stage, overall stage, maximum standardized uptake value (SUVmax) in staging PET, gross target volume (GTV)], and treatment [RT delivery, the use of peri-CCRT systemic therapy, RT break, eMLD50, eMLD60, eSCD50, and eSCD60]. These covariables were selected and modified by our experience in clinical practice and Taiwan Cancer Registry/National Health Insurance related studies (16-20), and were defined as the followings. Clinical stage was classified as T1-T3 vs. T4 for Tstage, N0-N1 vs. N2-N3 for N-stage and I-II vs. III for the overall stage. RT delivery was classified as image-guided radiotherapy (IGRT) or not. Peri-CCRT systemic therapy was classified as yes 


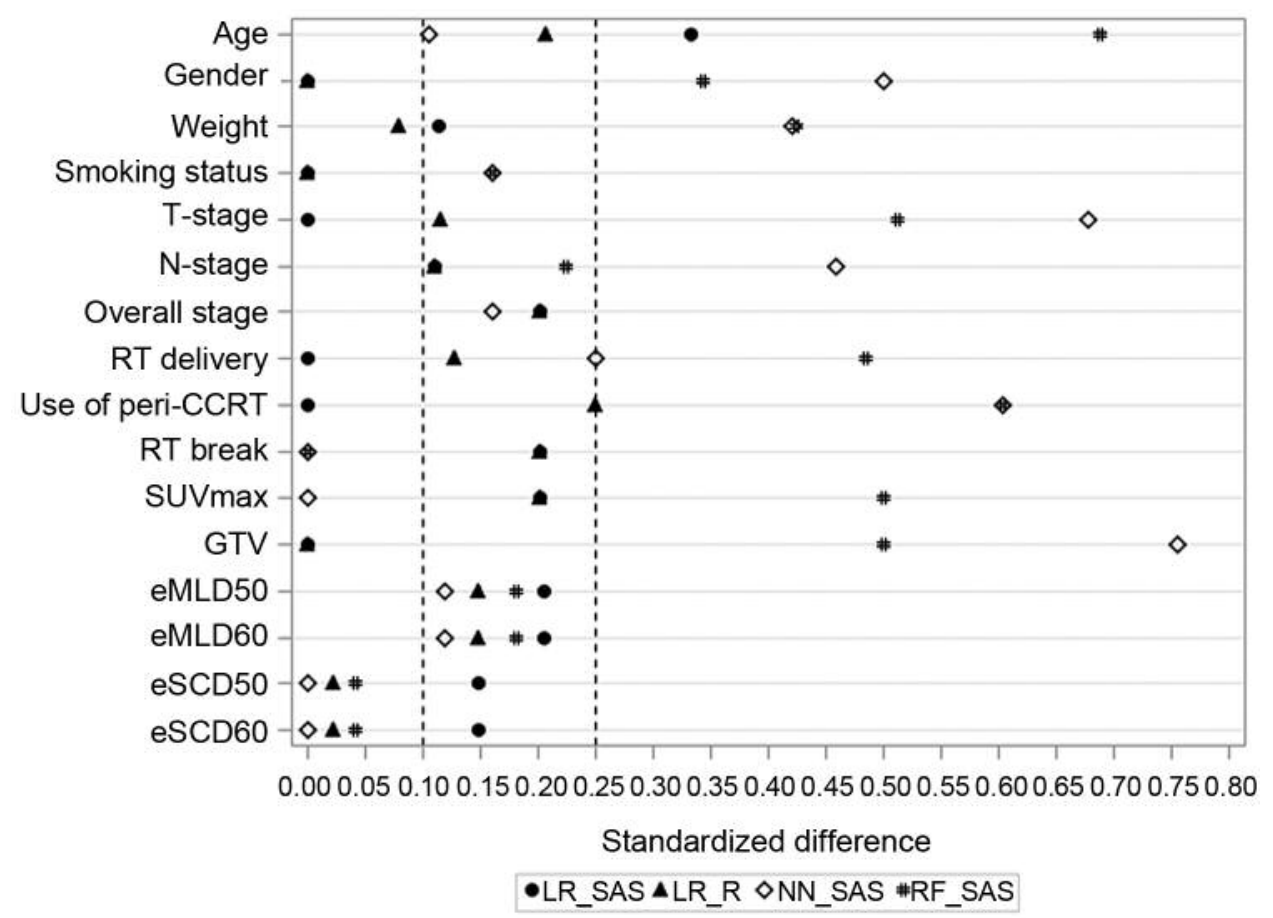

Figure 2. Standardized difference (SDif) via various methods (LR_SAS, LR_R, NN_SAS, and RF_SAS). LR_SAS: Propensity score (PS) estimated by logistic regression and PS matched by SAS software; LR_R: PS estimated by logistic regression and PS matched by $R$ software; NN_SAS: PS estimated by neuralnet and $P S$ matched by SAS software; RF_SAS: PS estimated by random forest and PS matched by SAS software; eMLD50: expected mean lung dose if radiotherapy delivered at $50 \mathrm{~Gy}$; eMLD60: expected mean lung dose if radiotherapy delivered at 60 Gy; eSCD50: expected spinal cord maximal dose if radiotherapy delivered at 50 Gy; eSCD60: expected spinal cord maximal dose if radiotherapy delivered at 60 Gy; GTV: gross target volume; IGRT: image-guided radiotherapy; peri-CCRT: peri-concurrent chemoradiotherapy; RT: radiotherapy; SUVmax: maximum standardized uptake value.

or no. The RT break interval was calculated by the exact RT duration (week) minus the expected RT duration (by 5 fractions per week) and classified as $>1$ week or $\leq 1$ week. As mentioned in the literature, SUVmax was classified as $\geq 5.6$ or $<5.6$ (21) and GTV was categorized as $\geq 27 \mathrm{ml}$ or not (22).

Statistical analysis. The software SAS 9.4 (SAS Institute, Cary, NC, USA) and R (R Development Core Team, R Foundation for Statistical Computing, Vienna, Austria) version 3.5.1 were used for statistical analyses. The propensity score method was used as advocated in the literature to balance the measured potential confounders $(23,24)$. The above covariables were used in the PS model construction using various methods to estimate the possible PS value as suggested in the literature (25-28) and then PS matching was performed (PSM, 1:1 paired matching). Finally, the balance of covariate was assessed via standardized difference (SDif) as suggested in several review papers $(25,29,30)$. The hazard ratio (HR) of death for OS, PFS and ECSS was compared using Cox proportional hazards model with a robust variance estimator (24). The survival rates were obtained from the death registry (follow-up until December 31, 2017 or death). The Evalue was also calculated as suggested in the literature (31) to evaluate the potential impact of potentially unmeasured confounder(s).

\section{Results}

Identification of the study population. Our study flow chart as suggested by the STROBE guideline (32) is depicted in Figure 1. The identified initial study population consisted of 73 clinical stage II-III unresected ESqCC adult patients receiving definitive CCRT (all treated with intensity-modulated radiotherapy) using either standard or high RT dose. PS values were estimated using LR, NN, RF and then PSM using $\mathrm{SAS}$ or R was performed. Figure 2 shows the distributions of SDif for each of the covariates applying various methods. About half of the covariables could not be moderately balanced (i.e., SDif $\leq 0.25$ ) (29) for PS estimated by NN or RF methods whereas most covariables (except age) could be moderately balanced for PS estimated by the LR method. PS estimated by the LR method and PSM estimated using R (optmatch package) could achieve better covariable balance when compared to PSM using SAS (SDif $\leq 0.25$ for all covariables in PSM using $\mathrm{R}$, and in PSM using $\mathrm{R}$ out performed PSM using SAS in 6 covariables while SAS outperformed $\mathrm{R}$ in 3 covariables). Therefore, the best approach 
Table I. Characteristics of unmatched and matched study population.

\begin{tabular}{|c|c|c|c|c|c|c|c|c|c|c|}
\hline & \multicolumn{4}{|c|}{ Unmatched population $(n=73)$} & \multirow[b]{3}{*}{$\operatorname{SDif}^{\dagger}$} & \multicolumn{4}{|c|}{ Matched study population $(n=36)$} & \multirow[b]{3}{*}{ SDif } \\
\hline & \multicolumn{2}{|c|}{ Standard RT dose } & \multicolumn{2}{|c|}{ High RT dose } & & \multicolumn{2}{|c|}{ Standard RT dose } & \multicolumn{2}{|c|}{ High RT dose } & \\
\hline & $\begin{array}{l}\text { Number or } \\
\text { mean }(\mathrm{sd}) \dagger\end{array}$ & $(\%)^{\dagger}$ & $\begin{array}{l}\text { Number or } \\
\text { mean }(\mathrm{sd})^{\dagger}\end{array}$ & $(\%)^{\dagger}$ & & $\begin{array}{l}\text { Number or } \\
\text { mean }(\mathrm{sd})^{\dagger}\end{array}$ & $(\%)^{\dagger}$ & $\begin{array}{l}\text { Number or } \\
\text { mean }(\mathrm{sd})^{\dagger}\end{array}$ & $(\%)^{\dagger}$ & \\
\hline Age (years old) & $58.00(6.49)$ & & $59.65(10.42)$ & & 0.191 & $58.00(6.49)$ & & $59.56(8.38)$ & & 0.208 \\
\hline \multicolumn{11}{|l|}{ Gender } \\
\hline Female & 0 & $(0)$ & 3 & (5) & 0.340 & 0 & $(0)$ & 0 & $(0)$ & 0 \\
\hline Male & 18 & $(100)$ & 52 & (95) & & 18 & $(100)$ & 18 & $(100)$ & \\
\hline Weight & $56.33(8.22)$ & & $58.35(12.87)$ & & 0.186 & $56.33(8.22)$ & & $57.00(8.51)$ & & 0.080 \\
\hline \multicolumn{11}{|l|}{ Smoking status } \\
\hline No & 2 & $(11)$ & 9 & (16) & 0.153 & 2 & $(11)$ & 2 & (11) & 0 \\
\hline Yes & 16 & (89) & 46 & $(84)$ & & 16 & (89) & 16 & (89) & \\
\hline \multicolumn{11}{|l|}{ T-stage ${ }^{\#}$} \\
\hline T2-T3 & 11 & $(61)$ & 40 & (73) & 0.249 & 11 & $(61)$ & 12 & $(67)$ & 0.116 \\
\hline $\mathrm{T} 4$ & 7 & (39) & 15 & (27) & & 7 & (39) & 6 & (33) & \\
\hline \multicolumn{11}{|l|}{$\mathrm{N}$-stage } \\
\hline N0-N1 & 10 & (56) & 26 & (47) & 0.166 & 10 & $(56)$ & 9 & $(50)$ & 0.111 \\
\hline $\mathrm{N} 2-\mathrm{N} 3$ & 8 & (44) & 29 & (53) & & 8 & (44) & 9 & (50) & \\
\hline \multicolumn{11}{|l|}{ Overall stage $\ddagger$} \\
\hline II & 2 & (11) & 6 & (11) & 0.006 & 2 & (11) & 1 & (6) & 0.202 \\
\hline III & 16 & (89) & 49 & (89) & & 16 & (89) & 17 & (94) & \\
\hline \multicolumn{11}{|l|}{ RT delivery } \\
\hline Non-IGRT & 14 & (78) & 34 & $(62)$ & 0.353 & 14 & (78) & 13 & (72) & 0.129 \\
\hline IGRT & 4 & (22) & 21 & (38) & & 4 & (22) & 5 & (28) & \\
\hline \multicolumn{11}{|l|}{$\begin{array}{l}\text { Use of peri-CCRT } \\
\text { systemic therapy }\end{array}$} \\
\hline No & 14 & (78) & 26 & (47) & 0.664 & 14 & (78) & 12 & $(67)$ & 0.25 \\
\hline Yes & 4 & (22) & 29 & (53) & & 4 & (22) & 6 & (33) & \\
\hline \multicolumn{11}{|l|}{ RT break [week] } \\
\hline$\leq 1$ & 16 & (89) & 48 & (87) & 0.050 & 16 & (89) & 17 & (94) & 0.202 \\
\hline$>1$ & 2 & (11) & 7 & (13) & & 2 & (11) & 1 & (6) & \\
\hline \multicolumn{11}{|l|}{ SUVmax } \\
\hline$<5.6$ & 2 & (11) & 5 & (9) & 0.067 & 2 & (11) & 1 & (6) & 0.202 \\
\hline$\geq 5.6$ & 16 & (89) & 50 & (91) & & 16 & (89) & 17 & (94) & \\
\hline \multicolumn{11}{|l|}{$\mathrm{GTV}[\mathrm{ml}]$} \\
\hline$<27$ & 0 & $(0)$ & 12 & (22) & 0.747 & 0 & $(0)$ & 0 & $(0)$ & 0 \\
\hline$\geq 27$ & 18 & $(100)$ & 43 & (78) & & 18 & (100) & 18 & $(100)$ & \\
\hline eMLD50 [cGy] & $1010.35(380.50)$ & & $915.36(308.73)$ & & 0.274 & $1010.35(380.50)$ & & $958.38(317.46)$ & & 0.148 \\
\hline eMLD60 [cGy] & $1212.42(456.60)$ & & $1098.44(370.47)$ & & 0.274 & $1212.42(456.60)$ & & $1150.06(380.95)$ & & 0.148 \\
\hline eSCD50 [cGy] & $3423.99(925.05)$ & & $3472.07(537.44)$ & & 0.064 & $3423.99(925.05)$ & & $3405.58(632.33)$ & & 0.023 \\
\hline eSCD60 [cGy] & $4108.79(1110.06)$ & & $4166.48(644.92)$ & & 0.064 & $4108.79(1110.06)$ & & $4086.69(758.80)$ & & 0.023 \\
\hline
\end{tabular}

eMLD50: Expected mean lung dose if radiotherapy delivered at $50 \mathrm{~Gy}$; eMLD60: expected mean lung dose if radiotherapy delivered at 60 Gy; eSCD50: expected spinal cord maximal dose if radiotherapy delivered at $50 \mathrm{~Gy}$; eSCD60: expected spinal cord maximal dose if radiotherapy delivered at 60 Gy; GTV: gross target volume; IGRT: image-guided radiotherapy; peri-CCRT: peri-concurrent chemoradiotherapy; RT: radiotherapy; SUVmax: maximum standardized uptake value; sd: standard deviation; SDif: standardized difference; ${ }^{\dagger}$ rounded; ${ }^{\ddagger}$ no $\mathrm{T} 1$ or stage I cases in the final study population.

was adopted (PS by LR and PSM by R) for the analysis and included 36 patients as the final study population (Table I).

Outcomes. After a median follow-up of ten months (range=282 months), 32 deaths were observed ( $15 \& 17$ for high RT dose \& standard RT dose groups, respectively). There was statistically significant difference when high RT dose was compared to standard RT dose (HR for death 0.554, $95 \% \mathrm{CI}=0.308-0.998, p=0.049)$. The observed HR of 0.554 could be explained away by an unmeasured confounder that was associated with both the selection of treatments and the live/death risk ratio of 2.187 (E-value) fold each, but weaker confounding could not do so. The Kaplan-Meier OS curve is shown in Figure 3. The results were not statistically significant 


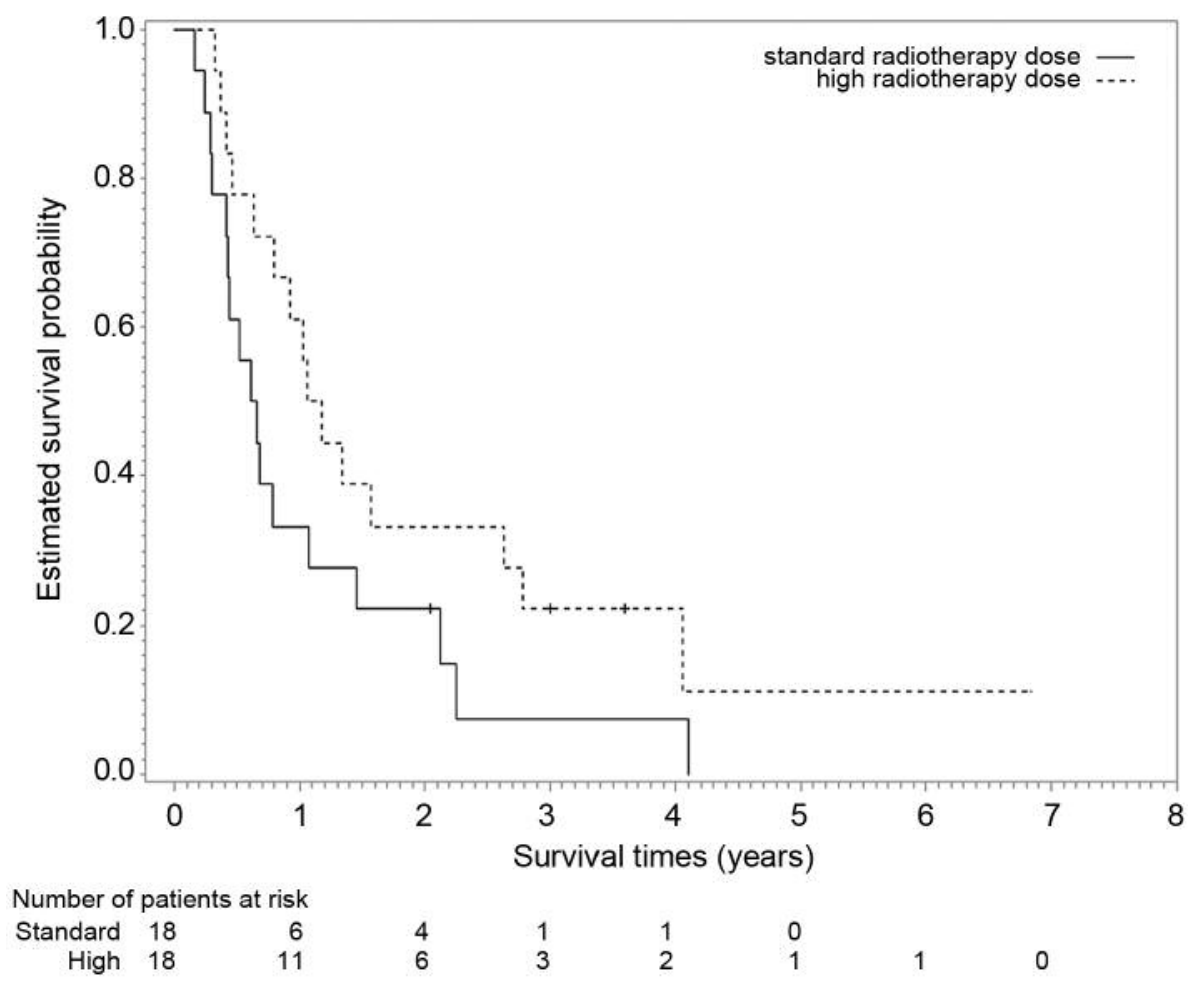

Figure 3. Kaplan-Meier overall survival curve (in years).

for PFS (HR 0.648, 95\%CI=0.346-1.214, $p=0.176$ ) and ECSS $(\mathrm{HR}=0.581,95 \% \mathrm{CI}=0.317-1.064, p=0.079)$.

\section{Discussion}

In this single institution retrospective study, the survival outcome of localized ESqCC patients treated with definitive CCRT using high radiotherapy dose was found to be better compared to that using standard dose, even after controlling for covariables including OAR dose.

Our results were comparable with the studies (12-14) mentioned in the 2018 review paper (11), as well as our previous population-based study (17) in that high dose was associated with better outcomes. However, the results of the current study might be more reliable because they were controlled for OAR dose which was not considered in the abovementioned previous studies. However, our current study was still a retrospective study, and a recent RCT (NCT01937208) published as a conference paper reported no statistically significant difference (33). Therefore, the full paper of this RCT is eagerly awaited.

There were several limitations to our study. Firstly, as a non-randomized study, was prone to potential unmeasured confounders although care was taken to include potential confounders like OAR dose which were not addressed by the studies mentioned above. Secondly, the impact of salvage treatment was not investigated (34). Finally, the sample size of our study was small.

Therefore, the interpretation of the results of our study is not definitive, but should rather be viewed as supplementary while waiting for ongoing phase 3 trials. In addition to the above RCT (NCT01937208), only one trial (NCT02556762) was found that compares simultaneous modulated accelerated boost versus standard dose by searching https://clinicaltrials.gov/ in Nov 2018 using keywords "Esophageal Cancer I concurrent chemoradiotherapylPhase 3".

In conclusion, definitive CCRT using a high radiotherapy dose showed improved survival outcomes for localized ESqCC patients compared to standard dose, even after controlling for covariables including OAR dose.

\section{Conflicts of Interest}

The Authors declare no conflicts of interest regarding this study.

\section{Acknowledgements}

This work was partly supported by Ministry of Science and Technology (MOST 107-2314-B-039-026-) and China Medical University Hospital (DMR-108-054). The corresponding Author would like to thank Dr. Ya Chen Tina Shih for her mentoring in health services research. 


\section{References}

1 Ferlay J, Soerjomataram I, Dikshit R, Eser S, Mathers C, Rebelo M, Parkin DM, Forman D and Bray F: Cancer incidence and mortality worldwide: sources, methods and major patterns in GLOBOCAN 2012. Int J Cancer 136: E359-E386, 2015.

2 Pennathur A, Gibson MK, Jobe BA and Luketich JD: Oesophageal carcinoma. Lancet 381: 400-412, 2013.

3 Chien CR, Lin CY and Chen CY: Re: Incidence of adenocarcinoma of the esophagus among white Americans by sex, stage, and age. J Natl Cancer Inst 101: 1428, 2009.

4 National Comprehensive Cancer Network Guidelines for Esophageal Cancers, version 2.2011. Available at: https://www.nccn.org/professionals/physician_gls/pdf/esophageal .pdf [free registration required]. Accessed June 24, 2011.

5 National Comprehensive Cancer Network Guidelines for Esophageal and Esophagogastric Junction Cancers, version 2.2018. Available at: https://www.nccn.org/professionals/ physician_gls/pdf/esophageal.pdf [free registration required]. Accessed October 23, 2018.

6 Stahl M, Mariette C, Haustermans K, Cervantes A, Arnold D and ESMO Guidelines Working Group: Oesophageal cancer: ESMO Clinical Practice Guidelines for diagnosis, treatment and followup. Ann Oncol 24: vi51-vi56, 2013.

7 Lordick F, Mariette C, Haustermans K, Obermannová R, Arnold D and ESMO Guidelines Committee: Oesophageal cancer: ESMO Clinical Practice Guidelines for diagnosis, treatment and follow-up. Ann Oncol 27: v50-v57, 2016.

8 Kuwano H, Nishimura Y, Oyama T, Kato H, Kitagawa Y, Kusano M, Shimada H, Takiuchi H, Toh Y, Doki Y, Naomoto Y, Matsubara H, Miyazaki T, Muto $M$ and Yanagisawa A: Guidelines for Diagnosis and Treatment of Carcinoma of the Esophagus April 2012 edited by the Japan Esophageal Society. Esophagus 12: 1-30, 2015.

9 Minsky BD, Pajak TF, Ginsberg RJ, Pisansky TM, Martenson J, Komaki R, Okawara G, Rosenthal SA and Kelsen DP: INT 0123 (Radiation Therapy Oncology Group 94-05) phase III trial of combined-modality therapy for esophageal cancer: high-dose versus standard-dose radiation therapy. J Clin Oncol 20: 1167-1174, 2002.

10 Yamoah K, Showalter TN and Ohri N: Radiation Therapy Intensification for Solid Tumors: A Systematic Review of Randomized Trials. Int J Radiat Oncol Biol Phys 93: 737-745, 2015.

11 Deng W and Lin SH: Advances in radiotherapy for esophageal cancer. Ann Transl Med 6: 79, 2018.

12 Suh YG, Lee IJ, Koom WS, Cha J, Lee JY, Kim SK and Lee CG: High-dose versus standard-dose radiotherapy with concurrent chemotherapy in stages II-III esophageal cancer. Jpn J Clin Oncol 44: 534-540, 2014.

13 Zhang Z, Liao Z, Jin J, Ajani J, Chang JY, Jeter M, Guerrero T, Stevens CW, Swisher S, Ho L, Yao J, Allen P, Cox JD and Komaki R: Dose-response relationship in locoregional control for patients with stage II-III esophageal cancer treated with concurrent chemotherapy and radiotherapy. Int J Radiat Oncol Biol Phys 61: 656-664, 2005.

14 Kim HJ, Suh YG, Lee YC, Lee SK, Shin SK, Cho BC and Lee CG: Dose-Response Relationship between Radiation Dose and Loco-regional Control in Patients with Stage II-III Esophageal Cancer Treated with Definitive Chemoradiotherapy. Cancer Res Treat 49: 669-677, 2017.
15 The American Joint Committee on Cancer (AJCC) Cancer Staging Manual, Seventh Edition. Available at: https://cancerstaging.org/ references-tools/deskreferences/Documents/AJCC\%207th\% 20Ed\%20Cancer\%20Staging\%20Manual.pdf. Accessed October 25, 2018.

16 Lin CY, Fang HY, Feng CL, Li CC and Chien CR: Costeffectiveness of neoadjuvant concurrent chemoradiotherapy versus esophagectomy for locally advanced esophageal squamous cell carcinoma: A population-based matched casecontrol study. Thorac Cancer 7: 288-295, 2016.

17 Chen CY, Li CC and Chien CR: Does higher radiation dose lead to better outcome for non-operated localized esophageal squamous cell carcinoma patients who received concurrent chemoradiotherapy? A population-based propensity-score matched analysis. Radiother Oncol 120: 136-139, 2016.

$18 \mathrm{Li} \mathrm{CC}$, Chen CY and Chien CR: Comparative effectiveness of image-guided radiotherapy for non-operated localized esophageal squamous cell carcinoma patients receiving concurrent chemoradiotherapy: A population-based propensity score matched analysis. Oncotarget 7: 71548-71555, 2016.

$19 \mathrm{Li} \mathrm{CC}$, Chen CY and Chien CR: Comparison of intensitymodulated radiotherapy vs. 3-dimensional conformal radiotherapy for patients with non-metastatic esophageal squamous cell carcinoma receiving definitive concurrent chemoradiotherapy: A population-based propensity-scorematched analysis. Medicine (Baltimore) 97: e10928, 2018.

20 Chen CY, Li CC and Chien CR: Neoadjuvant vs. definitive concurrent chemoradiotherapy in locally advanced esophageal squamous cell carcinoma patients. World J Surg Oncol 16: 141, 2018.

21 Yuan H, Tong DK, Vardhanabhuti V, Law SY, Chiu KW and Khong PL: PET/CT in the evaluation of treatment response to neoadjuvant chemoradiotherapy and prognostication in patients with locally advanced esophageal squamous cell carcinoma. Nucl Med Commun 37: 947-955, 2016.

22 Fan B, Fan P, Kong L, Sun X, Zhao S, Sun X, Fu Z, Zheng J, Ma L, Wang S, Hu M and Yu J: ${ }^{18} \mathrm{~F}$-deoxyglucose positron emission tomography/computed tomography to predict local failure in esophageal squamous cell carcinoma. Oncotarget 8 : 34498-34506, 2017.

23 Jagsi R, Bekelman JE, Chen A, Chen RC, Hoffman K, Shih YC, Smith BD and Yu JB: Considerations for observational research using large data sets in radiation oncology. Int J Radiat Oncol Biol Phys 90: 11-24, 2014.

24 Austin PC: The use of propensity score methods with survival or time-to-event outcomes: reporting measures of effect similar to those used in randomized experiments. Stat Med 33: 1242$1258,2014$.

25 Ali MS, Groenwold RH, Belitser SV, Pestman WR, Hoes AW, Roes $\mathrm{KC}$, Boer Ad and Klungel $\mathrm{OH}$ : Reporting of covariate selection and balance assessment in propensity score analysis is suboptimal: a systematic review. J Clin Epidemiol 68: 112-121, 2015.

26 Norman Matloff: Statistical regression and classification: From linear models to machine learning. 1st edition. Chapman \& Hall/CRC, 2017.

27 Jackson JW, Schmid I and Stuart EA: Propensity Scores in Pharmacoepidemiology: Beyond the Horizon. Curr Epidemiol Rep 4: 271-280, 2017.

28 Deist TM, Dankers FJWM, Valdes G, Wijsman R, Hsu IC, Oberije C, Lustberg T, van Soest J, Hoebers F, Jochems A, El 
Naqa I, Wee L, Morin O, Raleigh DR, Bots W, Kaanders JH, Belderbos J, Kwint M, Solberg T, Monshouwer R, Bussink J, Dekker A and Lambin P: Machine learning algorithms for outcome prediction in (chemo)radiotherapy: An empirical comparison of classifiers. Med Phys 45: 3449-3459, 2018.

29 Garrido MM, Kelley AS, Paris J, Roza K, Meier DE, Morrison RS and Aldridge MD: Methods for constructing and assessing propensity scores. Health Serv Res 49: 1701-1720, 2014.

30 Yao XI, Wang X, Speicher PJ, Hwang ES, Cheng P, Harpole DH, Berry MF, Schrag D and Pang HH: Reporting and guidelines in propensity score analysis: A systematic review of cancer and cancer surgical studies. J Natl Cancer Inst 109(8): 2017. doi: 10.1093/jnci/djw323.

31 VanderWeele TJ and Ding P: Sensitivity analysis in observational research: introducing the E-value. Ann Intern Med 167: 268-274, 2017.

32 von Elm E, Altman DG, Egger M, Pocock SJ, Gøtzsche PC, Vandenbroucke JP and STROBE Initiative: The Strengthening the Reporting of Observational Studies in Epidemiology (STROBE) Statement: guidelines for reporting observational studies. Int J Surg 12: 1495-1499, 2014.
$33 \mathrm{Xu}$ YJ, Zhu WG, Zheng X, Wang WW, Li JC, Huang R, He H, Chen JX, Liu LP, Sun ZW, Yang XM, He HJ, Zeng M, Pu J, Hu WY, Bao Y, Liu ZG, Ma J and Chen M: A multi-center, randomized, prospective study evaluating the optimal radiation dose of definitive concurrent chemoradiation for inoperable esophageal squamous cell carcinoma. J Clin Oncol 36: 4013, 2018.

34 Urschel JD, Ashiku S, Thurer R and Sellke FW: Salvage or planned esophagectomy after chemoradiation therapy for locally advanced esophageal cancer--a review. Dis Esophagus 16: 60$65,2003$.

Received November 22, 2018

Revised December 9, 2018

Accepted December 10, 2018 